\title{
Spinal cord dysfunction complicating meningococcal meningitis
}

\author{
Javaid Khan, Irfan Altafullah and Mohammed Ishaq
}

Department of Medicine, The Aga Khan University and Hospital, P.O. Box 3500, Stadium Road, Karachi-748001, Pakistan.

Summary: A 29 year old male developed paraplegia during the acute phase of meningococcal meningitis. Possible mechanisms for this unusual complication are discussed and the literature regarding spinal cord complications of pyogenic meningitis is reviewed.

\section{Introduction}

Well known complications of meningitis include cranial nerve palsies, hydrocephalus, seizures, subdural effusion, cerebral venous thrombosis, hemiplegia and water intoxication. ${ }^{1}$ Spinal cord dysfunction has rarely been described as a complication.

\section{Case report}

A previously healthy 29 year old Iranian male presented with a 48-hour history of fever, headache, and vomiting followed by confusion and drowsiness. On admission his temperature was $37^{\circ} \mathrm{C}$, blood pressure $110 / 70 \mathrm{mmHg}$ and pulse rate 70 beats per minute. There was marked neck stiffness and Kernig's sign. Pupillary reactions to light and fundoscopy were normal. A purpuric rash was seen over the abdomen and thighs. He was unresponsive to painful stimulation. Muscle tone was decreased in the lower extremities. Spontaneous movements were seen only in the upper extremities. There was impaired perception of pinprick below the T10 level as judged by facial grimacing. Deep tendon reflexes were normal in the upper extremities and absent in the legs. Plantar responses were flexor.

Laboratory investigations showed a white cell count of $17 \times 10^{9} / 1$. Serum electrolytes, urinalysis, coagulation parameters, and serum fibrinogen degradation products were all normal. The cerebrospinal fluid (CSF) contained $16.6 \times 10^{9} \mathrm{WBC} / 1$ ( $95 \%$ polymorphonuclear leukocytes), $748 \mathrm{mg} / \mathrm{dl}$ of protein, $<0.4 \mathrm{mmol} / 1$ of glucose and numerous Gram-negative diplococci: meningococci were grown.

Correspondence: Javaid Khan, M.R.C.P.

Accepted: 8 September 1989
Intravenous benzylpenicillin ( 24 million units/ day) and chloramphenicol ( $4 \mathrm{~g} /$ day) were begun. The following day bilateral abducent nerve palsies, upper motor neurone type right facial weakness and a dilated right pupil were evident. Computerized tomography $(\mathrm{CT})$ of the head revealed cerebral oedema. Intense enhancement of the basal cisterns was seen following intravenous contrast indicating an inflammatory process involving the basal meninges. Intravenous dexamethasone and mannitol were begun for treatment of increased intracranial pressure.

The patient improved over the next few days with gradual recovery of cognitive function. However, the paraparesis remained unchanged. Myelography on day 9 was normal and the CSF showed 176 white cells $/ \mathrm{mm}^{3}, 79 \mathrm{mg} / \mathrm{dl}$ of protein, and $4.6 \mathrm{mmol} / \mathrm{l}$ of glucose. The first signs of improvement of the paraplegia were seen on day 20 and a week later the patient was walking with assistance. Repeat CT scan of the head showed resolution of cerebral oedema and mild diffuse cortical atrophy. On discharge there was mild paraparesis with hyper-reflexia in the legs. Pinprick sensation, vibration and joint position were normal. Babinski's signs were present bilaterally. Persistent urinary incontinence required an indwelling catheter.

\section{Discussion}

Spinal cord involvement has seldom been described as a feature of meningococcal meningitis. Farmer, reporting on 300 cases, observed focal neurological complications in 26 patients but none had symptoms suggesting cord involvement. ${ }^{2}$ Turner described two patients who developed a 'poliomyelitic type' spinal cord syndrome during the course of acute meningococcal meningitis. ${ }^{3} \mathrm{He}$ also des- 
cribed two other patients who developed progressive leg weakness months to years after an episode of pyogenic meningitis. Gotshall described a 20 year old man with paraplegia, normal myelography, with the lesion clinically localized to the conus medullaris. ${ }^{4}$ A similar syndrome was described in a two year old girl with meningococcal meningitis. ${ }^{5}$ Partial Brown-Sequard syndrome may complicate meningococcal meningitis. ${ }^{6}$ In one patient, paraplegia was the presenting feature of meningococcal meningitis.?

In several cases of quadriplegia complicating bacterial meningitis, cardiorespiratory arrest has preceded, and presumably caused, development of the cord syndrome. Three such patients with Haemophilus influenzae and one with meningococcal meningitis have been described.$^{8-10}$ In a review of the literature, Seay noted that in young children and infants, cervical lesions were common while in adolescents and adults midthoracic and lumbar lesions predominate. ${ }^{8}$

Several mechanisms may lead to spinal cord involvement in bacterial meningitis. Delayed complications such as paraparesis, sensory loss, and urinary incontinence may develop from vascular insufficiency of the cord secondary to arachnoiditis. $^{2}$ Hypoxia and systemic hypotension, with hypoperfusion of the vulnerable 'watershed' area of the cord, may play an important role in patients who suffer cardiorespiratory arrest during the course of pyogenic meningitis. Vascular compromise in the acute phase of meningitis may result from an inflammatory vasculitis. Adams noted endothelial cell swelling of small and medium sized

\section{References}

1. Dodge, P.R. \& Swartz, M.N. Bacterial meningitis - A review of selected aspects. $N$ Engl $J$ Med 1965, 272: 954-960 $1003-1010$.

2. Farmer, T.W. Neurological complications during meningococcal meningitis treated with sulfonamide drugs. Arch Intern Med 1945, 76: 201-209.

3. Turner, J.W.A. Spinal cord lesions in cerebrospinal fever: report of four cases. Lancet 1948, i: 398-402.

4. Gotshall, R.A. Conus medullaris syndrome after meningococcal meningitis. $N$ Engl J Med 1972, 286: 882-883.

5. Wilkins, L. An unusual complication of meningitis: Lesions of the conus medullaris. AJDC 1925, 29: 67-69.

6. Graus, F., Arbizu, T. \& Rufi, G. Partial Brown-Sequard's syndrome and meningococcal meningitis. Arch Neurol 1981, 88: 602 .

7. Boothman, B.R., Bamford, J.M. \& Parsons, M.R. Paraplegia as a presenting feature of meningococcal meningitis. $J$ Neurol Neurosurg Psychiatry 1988, 51: 1241.

8. Seay, A.R. Spinal cord dysfunction complicating bacterial meningitis. Arch Neurol 1984, 41: 545-546. blood vessels during the acute phase of $H$. influenzae meningitis, although thrombosis was infrequent. $^{12}$ Cerebral angiography during $H$. influenzae meningitis revealed narrowing of large vessels and occlusions of small vessels with retrograde collateral flow and slowing of the circulation. Follow up angiograms in two patients, showed resolution of the angiographic abnormalities. ${ }^{13,14}$ Gado et al. believed that these findings were caused by an inflammatory arteritis of the vessel wall. ${ }^{13}$ Because one would expect the inflammatory process to be subsiding after several days of appropriate therapy, other authors believe the angiographic changes are caused by vascular spasm, similar to that seen in aneurysmal subarachnoid haemorrhage. ${ }^{14}$

Our patient presented with flaccid areflexic paraplegia with a lower thoracic sensory level. This evolved into spastic paraparesis with bilateral extensor plantar responses. Although pathological confirmation is lacking, because there was preservation of dorsal column sensations, we postulate the cause was occlusion of a penetrating branch of the anterior spinal artery. The significant recovery of function in our patient is similar to a patient described by Boothman et al. ${ }^{7}$

In uncomplicated meningitis signs are bilateral, symmetrical, and of similar extent in upper and lower limbs. Any deviation from this pattern suggests a focal complication rather than a diffuse meningitic process. Early elimination of other causes, such as epidural abscess, and aggressive treatment of the meningitis should lead to a favourable outcome.

9. DeSousa, Al, Kleinman, M.B. \& Mealy, J. Quadriplegia and cortical blindness in Hemophilus influenza meningitis. $J$ Pediatr 1978, 93: 253-254.

10. Tal, Y., Crichton, J.U., Dunn, H.G. et al. Spinal cord damage: A rare complication of purulent meningitis. Acta Paediatr Scand 1980, 69: 471-474.

11. Glista, G.G., Sullivan, T.D. \& Brumlik, J. Spinal cord involvement in acute bacterial meningitis. JAMA 1980, 243: $1362-1363$.

12. Adams, R.D., Kubik, C.S. \& Bonner, F.J. The clinical and pathological aspects of influenza meningitis. Arch Pediatr 1948, 65: 354-376.

13. Gado, M., Axley, J., Appleton, B. \& Prensky, A. Angiography during the acute and post-treatment phase of Hemophilus influenza meningitis. Radiology 1974, 110: 439-444.

14. Igarashi, M., Gilmartin, R.C., Gerald, B., Wilburn, F. \& Jabbour, J. Cerebral arteritis and bacterial meningitis. Arch Neurol 1984, 41: 531-535. 